\title{
Does chronic supplementation of the diet with dietary fibre extracted from pea or carrot affect colonic motility in man?
}

\author{
BY CLAIRE GUÉDON ${ }^{1}$, PHILIPPE DUCROTTÉ ${ }^{1}$, JEAN MICHEL ANTOINE ${ }^{2}$, \\ PHILIPPE DENIS', RAYMOND COLIN AND ERIC LEREBOURS ${ }^{1}$ \\ ${ }^{1}$ Groupe de Physiopathologie Digestive et Nutritionnelle, Hôpital Charles Nicolle, 1 rue de Germont, \\ F-76031 Rouen Cedex, France \\ ${ }^{2} B S N$, 6 rue de Téhéran, F-75006 Paris, France
}

(Received 20 March 1995 - Revised 4 October 1995 - Accepted 15 November 1995)

\begin{abstract}
The aim of the present study was to assess, in healthy volunteers and under physiological conditions, the acceptability, clinical tolerance and effects on colonic motility of chronic supplementation of the usual diet with new dietary fibre sources. Three studies were carried out, one after a period of habitual diet, and two after randomized 3-week periods of supplementation with fibre extracted either from pea hulls or carrots, added to the meals as a fine powder. The $\mathbf{2 4} \mathrm{h}$ motility was recorded on an unprepared colon at five levels to determine the initiation site and the number of high amplitude propagated contractions (HAPC) and to quantify motor activity every $30 \mathrm{~min}$, particularly in the two periods following lunch and breakfast. With the habitual diet the motility pattern was an irregular alternation of quiescence and sporadic non-propagated contractions. HAPC always started from the ascending colon and occurred mainly after breakfast. With either type of fibre the $24 \mathrm{~h}$ motor profiles, the $24 \mathrm{~h}$ variations and the number of HAPC were not significantly modified but a more distal initiation of HAPC was found. The colonic postprandial motor response was more diffuse after dietary enrichment with carrot fibre than after enrichment with pea-hull fibre. In healthy volunteers the long-term addition of fibre extracted from pea hulls and carrots to the usual diet was easy and well-tolerated without clinical side-effects, but with limited colonic motor effects. However, the more distal initiation of HAPC observed could be deleterious.
\end{abstract}

Dietary fibre: Colonic motility

Dietary guidelines from the World Health Organization have recommended an average daily intake of $18 \mathrm{~g}$ dietary fibre, in order to prevent gastrointestinal diseases, mainly largebowel cancer (Spiller, 1986). The preventive effect of fibre on carcinogenesis seems to depend on its interaction with another food component such as meat or fat.

To be acceptable for long-term use, supplementation to this level of dietary fibre requires several conditions: (a) easy ingestion of the effective amount of $18 \mathrm{~g}$; (b) good digestive tolerance, without side-effects such as bloating, flatulence or diarrhoea (in previous trials these side effects were responsible for the interruption of the chronic enrichment of the diet with fibre in 15-35\% of the subjects); (c) the maintenance of the prevailing physiological status of the subject, especially colonic physiology as dietary fibre is shown to be mainly metabolized and active in the large bowel. Among physiological conditions it is important to consider the maintenance of the normal colonic motor pattern because fibre may affect colonic motility and interfere with other colonic functions, such as water and electrolyte absorption or short-chain fatty acid production by colonic microflora.

To reduce digestive intolerance and to facilitate chronic intake a new type of fibre is now available to consumers. This new fibre, mainly characterized by a very small particle size, is presented as a fine powder to facilitate its incorporation into cooked dishes. 
The aims of the present study were: $(a)$ to test if this new type of fibre was easy to ingest and well tolerated; $(b)$ to record in the unprepared whole colon of healthy volunteers the motor profiles obtained after a 3-week supplementation with new dietary fibre sources; and (c) to compare these motor profiles with those obtained in the same volunteers eating their habitual diet, not supplemented with dietary fibre.

\section{MATERIALS AND METHODS}

\section{Subjects}

Six healthy male volunteers aged 22-28 (mean 24 ) years were included in the study. None had a history of gastrointestinal disease, use of medications or previous abdominal surgery. All had a normal bowel habit, defined as a stool frequency between three bowel movements per day and three bowel movements per week (Drossman et al. 1982).

Written informed consent was obtained from all subjects. The study protocol was approved by the Ethical Committee of the Medical School of the University of Rouen.

\section{Diets}

Each of the six volunteers was studied three times: once during a basal study with his habitual diet and once after each of two 3-week periods during which the diet was chronically supplemented with two different types of dietary fibre extracted either from peas (Sofalite R F 179-80, Sofalia, Paris La Défense, France) or carrots (ARD, Compiègne, France).

The average daily consumption of fibre during the habitual diet was evaluated by means of a questionnaire. This survey concerned the previous consecutive $7 \mathrm{~d}$ just before the study. The questionnaire was given prospectively to the volunteers who recorded their own diet habits during that week. The daily consumption of fibre in these $7 \mathrm{~d}$ was then calculated by a dietitian using Englyst's table (Englyst, 1981).

Fibre was obtained from pea hulls and carrots by mechanical processes (grinding, airclassification, sieving and drying). Both types of fibre had a similar, very fine granulometry $(<100 \mu \mathrm{m})$. They were selected after a preliminary study involving twenty-seven healthy volunteers (C. Guédon and P. Ducrotté, unpublished results) demonstrating that their good palatability allowed chronic supplementation of the diet. The contents of cellulose, hemicellulose, lignin and pectin, the fermentability and the hygroscopic coefficient were determined at INRA, Nantes, France using a methodology previously described (Salvador et al. 1993). These variables were different for the two types of fibre (Table 1). Daily supplementation of the diet was achieved by sprinkling $15 \mathrm{~g}$ of the dietary fibre on some of the components of the three daily meals. For each subject the order of the three diets was determined by randomization before the beginning of the study. During the two periods of supplementation the diet was not standardized, except for the amount of fibre. These two periods were separated by a wash-out time of at least 1 week of habitual diet.

Each volunteer had to record in a diary stool frequency, stool consistency (hard, soft or watery) and the occurrence of bloating, flatulence, nausea, vomiting, diarrhoea (more than three stools/d) or abdominal pain during each of the three periods of the study.

\section{Manometric technique}

Intestinal tube. A $5 \mathrm{~m}$ long radio-opaque multilumen polyvinyl tube with eight separate catheters bonded together was used (Marquat, Boissy-Saint-Léger, France). A small Hg bag was attached to the distal tip. A balloon placed around the $\mathrm{Hg}$ bag was inflated to facilitate the progression of the tube. Distal ends of the catheters were opened every $150 \mathrm{~mm}$, with the last port located at $100 \mathrm{~mm}$ from the $\mathrm{Hg}$ bag. 
Table 1. Characteristics of the two types of fibre tested in the present study

\begin{tabular}{lcc}
\hline \multicolumn{1}{c}{ Type of fibre $\ldots$} & Pea-hull & Carrot \\
\hline Particle size $(j \mathrm{~m})$ & $<100$ & 60 \\
Hygroscopic coefficient $(\%)$ & $3 \cdot 5$ & 8.0 \\
Cellulose $(\mathrm{g} / \mathrm{kg})$ & 680 & 313 \\
Hemicellulose + pectin $(\mathrm{g} / \mathrm{kg})$ & 250 & 675 \\
Lignin $(\mathrm{g} / \mathrm{kg})$ & 70 & 13 \\
\hline
\end{tabular}

Recording system. The colonic motility was recorded using a manometric system. The technique was based on the hydraulic capillary infusion system described by Arndorfer $e t$ al. (1977) for oesophageal manometry. The recording sites of the intestinal tube were connected to eight Statham P23ID transducers, themselves connected to a computer via an amplifier and an analogue-to-digital converter (2ERL, Rennes, France).

For the computerized analysis, pressure changes were sampled at $20 \mathrm{~Hz}$ and stored on the hard disk of an IBM-PC computer. Recorded data were then processed using software developed by 2ERL-Lomatech (Rennes, France). This program included the following steps: peak detection, artifact rejection and calculation of the area under the curve (AUC) of each peak. A peak was defined as a data point preceded by a change in pressure greater than $10 \mathrm{mmHg}$ and succeeded by a change in pressure greater than $10 \mathrm{mmHg}$. To ignore the baseline variability induced by the subject's respiration, the system was set to reject variations within $10 \mathrm{mmHg}$ of the baseline. Artifacts were defined as contractions above $10 \mathrm{mmHg}$, whatever their amplitude, occurring simultaneously in all channels. An algorithm was designed to search for simultaneous pressure waves in all channels. Events detected this way were excluded from further analysis. Remaining pressure changes were then analysed as phasic colonic contractions when the duration of the pressure wave before and after a peak lasted between 2.5 and $15 \mathrm{~s}$. This time window was defined as the mean duration $\pm 2 \mathrm{SD}$, calculated manually on 200 successive colonic contractions. AUC was then calculated by integrating pressure from the beginning to the end of the wave.

The results obtained from computerized analysis were validated before the study by a comparison with the findings of a visual and manual analysis performed by two separate observers. The analysis of 450 successive colonic pressure waves demonstrated that it was possible to recognize $88 \%$ of the contractions and to reject all artifacts. The comparison between AUC calculated by the computer and AUC calculated manually by a semiautomatic method with an X-Y graphic table demonstrated an excellent correlation between the two methods, whether colonic phases occurred $(r 0.88, P<0.001)$ or not (r $0.92, P<0.001)$.

Colonic intubation. Each volunteer was intubated three times. One of the three intubations was performed during the habitual diet which was not supplemented with dietary fibre. The other two intubations were done just at the end of each period of supplementation. Each time, the tube was set in place without preparation of the colon, as previously described (Picon et al. 1992). All subjects were intubated through the nose after an overnight fast and the migration of the tube through the pylorus was assessed by X-ray examination. The distal balloon was inflated after passing the pylorus and the subject was sent home with the external part of the manometric tube stored in his coat pocket. The tube then migrated spontaneously along the small intestine and the colon. During this migration of the probe, the volunteer's social and physical activities remained normal. The distal balloon of the probe reached the anus with a mean delay of 72 (range 48-144) h. Then, 
it was taped to the anal margin and the subject returned to the hospital unit for the manometric recording.

The position of the colonic recording sites was determined on a plain film of the abdomen. Sites were selected among the eight catheters in order to record the colonic motor activity at the following levels: ascending colon, right transverse colon, left transverse colon, descending and sigmoid colon. In each volunteer the same recording sites were selected for the three manometric studies to facilitate interstudy comparisons.

General protocol of the $24 \mathrm{~h}$ recording. Colonic motor activity was recorded continuously from 09.00 hours to 09.00 hours the following morning in recumbent subjects.

After $4 \mathrm{~h}$ of recording fasting motility a standardized $4184 \mathrm{~kJ}$ meal was given at 13.00 hours. The composition of the meal was as follows: beef $(100 \mathrm{~g})$, one egg, French beans $(125 \mathrm{~g})$, noodles (165 g), butter (15 g), two dry toasts, one yoghurt (125 g), and sugar $(10 \mathrm{~g})$. This test meal provided energy in the following proportions: fat $35 \%$, carbohydrate $40 \%$ and protein $25 \%$. The liquid components of the meal were coffee $(125 \mathrm{ml})$ and water $(300 \mathrm{ml})$. In the two studies performed during the periods of chronic supplementation with dietary fibre, $15 \mathrm{~g}$ fibre powder was sprinkled on this standardized meal.

The subjects remained fasting until 07.00 hours the following morning when a continental breakfast was given, (four dry toasts, butter $(30 \mathrm{~g})$, sugar $(10 \mathrm{~g})$, jam (30 g) and coffee). This meal provided $1925 \mathrm{~kJ}$ : fat $50 \%$, carbohydrate $45 \%$ and protein $5 \%$ of energy. During the $24 \mathrm{~h}$ recording, volunteers rested in bed.

\section{Analysis of data}

For each $24 \mathrm{~h}$ recording the motor pattern analysis included the total recording time and the following successive periods: (1) the first basal period (09.00 to 13.00 hours); (2) the $4 \mathrm{~h}$ postprandial period (Snape et al. 1978) from 13.00 to 17.00 hours during which three periods were analysed separately: first half-hour following lunch, early postprandial period (13.00 to 15.00 hours) and late postprandial period (15.00 to 17.00 hours) according to Sarna's (1991) description; (3) a second fasting period from 17.00 to 07.00 hours; and (4) awakening and breakfast period the next day ( 07.00 to 09.00 hours).

Analysis was both visual and computerized. Visual analysis by two separate observers aimed at identifying high-amplitude propagated contractions (HAPC) defined as regular contractions with the following criteria: amplitude $>100 \mathrm{mmHg}$, propagation on at least two consecutive recording sites, occurrence as a single contraction or a burst of three or four contractions (Narducci et al. 1987; Bassotti \& Gaburri, 1988; Soffer et al. 1989; Crowell et al. 1991; Bassotti et al. 1992).

Computerized analysis included two items for each successive $30 \mathrm{~min}$ period: number of pressure waves and AUC (mmHg.s), both used as a colonic motor index.

\section{Statistical analysis}

To take into account the intersubject variability of the motor profile (Bassotti et al. 1989), volunteers were considered as their own controls and the statistical analysis was performed using ANOVA and Wilcoxon's non-parametric test for paired data. This analysis was done on the motility patterns calculated from the whole recording, and on those calculated during the successive periods defined previously. Qualitative variables (site of occurrence of HAPC) were tested by the $\chi^{2}$ test.

\section{RESULTS}

Clinical aspects

The chronic supplementation of the diet with fibre was well tolerated by all six volunteers during each 3-week period of supplementation and fibre was easily ingested each day. No 
Table 2. High amplitude propagated contractions in male subjects eating their habitual diet (no additional fibre) or diets containing $15 \mathrm{~g}$ fibre from pea hulls or carrots $/ \mathrm{d}^{*}$

\begin{tabular}{|c|c|c|c|}
\hline & $\begin{array}{c}\text { No additional } \\
\text { fibre }\end{array}$ & $\begin{array}{c}\text { Fibre from } \\
\text { pea hulls }\end{array}$ & $\begin{array}{c}\text { Fibre from } \\
\text { carrots }\end{array}$ \\
\hline Contractions per subject $(n)$ & $\begin{array}{c}1.5 \\
(0-12)\end{array}$ & $\begin{array}{c}6.5 \\
(1-10)\end{array}$ & $\begin{array}{c}3 \\
(1-11)\end{array}$ \\
\hline \multicolumn{4}{|l|}{$\begin{array}{l}\text { Time of occurrence } \\
\text { during recording }\end{array}$} \\
\hline Initial basal period & $\begin{array}{c}0 \\
(0-3)\end{array}$ & $\begin{array}{c}0 \\
(0-2)\end{array}$ & $\begin{array}{c}0 \\
(0-6)\end{array}$ \\
\hline Early postprandial period & $\begin{array}{c}0 \\
(0-2)\end{array}$ & $\begin{array}{c}0 \\
(0-2)\end{array}$ & $\begin{array}{c}0 \\
(0-2)\end{array}$ \\
\hline Late postprandial period & $\begin{array}{c}0 \\
(0-4)\end{array}$ & $\begin{array}{c}0 \\
(0-1)\end{array}$ & $\begin{array}{c}0 \\
(0-3)\end{array}$ \\
\hline Nocturnal period & $\begin{array}{c}0 \\
(0-3)\end{array}$ & $\begin{array}{c}0 \\
(0-5)\end{array}$ & $\begin{array}{c}0 \\
(0-2)\end{array}$ \\
\hline Breakfast time & $\begin{array}{r}0.5 \\
(0-2)\end{array}$ & $\begin{array}{r}2 \cdot 5 \\
(0-7)\end{array}$ & $\begin{array}{c}3 \\
(1-4)\end{array}$ \\
\hline \multicolumn{4}{|l|}{ Site of occurrence $(\%) \ddagger$} \\
\hline Ascending colon & 100 & 65 & 37 \\
\hline Transverse colon & 0 & 35 & 47 \\
\hline Descending colon & 0 & 0 & 16 \\
\hline
\end{tabular}

* For details of diets and procedures, see pp. 52-54.

$\uparrow$ Values are medians with ranges in parentheses.

$\$$ Values for site of occurrence were significantly different for the comparisons: no additional fibre $v$, added fibre $(P<0.001)$, no additional fibre $v$. pea fibre $(P<0.001)$ and no additional fibre $v$. carrot fibre $(P<0.001)$.

volunteer notified abdominal symptoms, change in bowel habits or in stool aspect and consistency. The daily stool frequency was unchanged from 1-2 bowel movement(s).

\section{Technical aspects}

The probe induced no side-effect during its migration nor in the $24 \mathrm{~h}$ recording sessions. The physical activity of all volunteers was normal during the migration of the probe. No study was interrupted because of technical problems related to the migration of the tube.

We were able to record colonic motility at the same four different levels (ascending colon, right and left transverse colon, descending colon) in the six volunteers for the three $24 \mathrm{~h}$ recording sessions. Sigmoid motility observed in all volunteers with both types of dietary fibre could be recorded during the normal diet period in only two subjects.

\section{Motor results}

High amplitude propagated contractions (HAPC). HAPC were recorded in each study, except in two subjects during the period with the habitual diet. Their number tended to be higher during the supplementation of the diet with fibre from pea hulls, but this difference was never significant (Table 2). All HAPC were aborally propagated. In all studies, HAPC occurred mainly after waking up in the morning and were rare during the nocturnal period of recording (Table 2). Most HAPC started in the right colon (70.5\% for all eighteen recordings). Our most important finding was that their initiation was different in the three studies: constant initiation in the right colon with the habitual diet; more distal initiation with the two other regimens. This difference between the diets supplemented or not with fibre $(P<0.001)$ and between the diets supplemented with each type of fibre was significant $(P<0.001)$ (Table 2). None of the HAPC was associated with a crampy urge to defecate. 


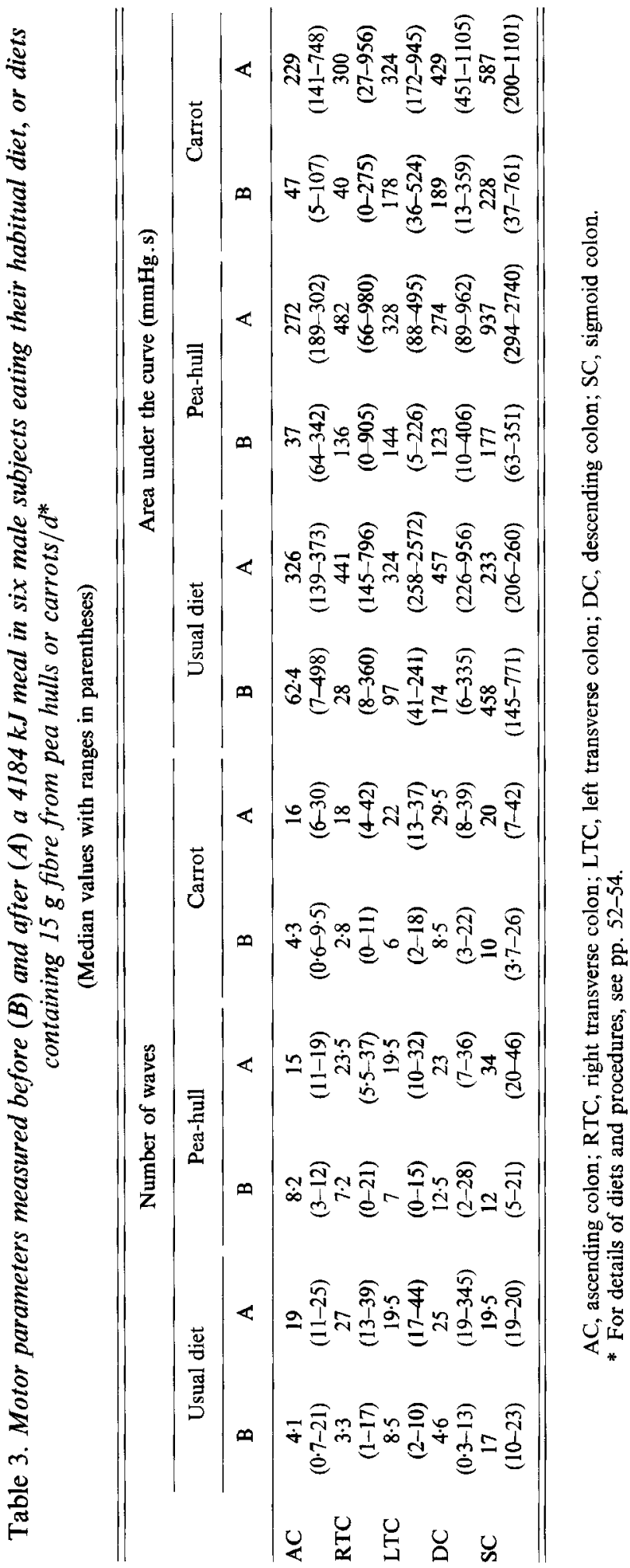



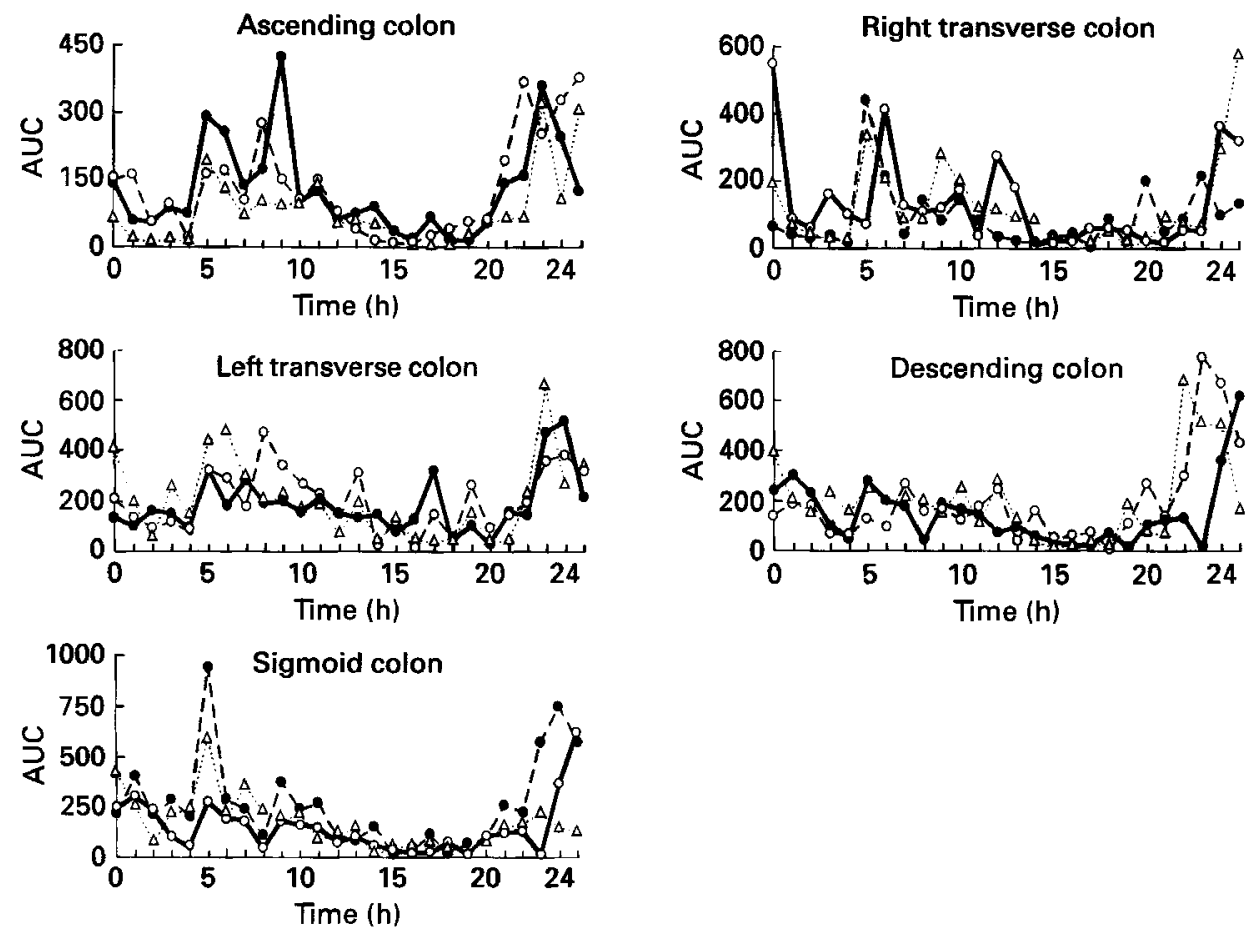

Fig. 1. Median area under the curve (AUC) values (mmHg.min) measured at five sites in the large intestine, for six male subjects consuming their habitual diet $(O)$, and diets supplemented with $15 \mathrm{~g}$ fibre from pea hulls $(O)$ or carrots $(\triangle)$ daily. For details of diets and procedures, see pp. 52-54.

Area under the curve and number of pressure waves: (a) Recording during usual diet. Colonic motor activity between HAPC was characterized by an irregular alternation of quiescence and sporadic non-propagated contractions, as previously described (Narducci et al. 1987; Bassotti et al. 1989). In all subjects the AUC and the number of pressure waves (NW) fluctuated widely at each colonic level (Table 3, Figs. 1 and 2). A high inter-subject variability of the $24 \mathrm{~h}$ motor profile was observed at each level.

At all levels, AUC and NW were low before lunch and minimal during the night (Figs. 1 and 2). After lunch the AUC and the NW values for the $4 \mathrm{~h}$ total postprandial period, for the first $2 \mathrm{~h}$, and for the second half of the postprandial period were not significantly different from those calculated during the basal period. Nevertheless, a significant increase of AUC and NW, when compared with those found before lunch, was demonstrated during the first $0.5 \mathrm{~h}$ after lunch. This increase, observed at all levels, was significant in the left transverse $(P<0.03)$ and the descending colon $(P<0.03)$ but not in the ascending colon or the sigmoid (Table 3).

A second significant increase of AUC and NW was observed in every subject at all levels after awakening $(P<0.01)$.

(b) Recordings during the diets supplemented with pea-hull or carrot fibre. AUC and NW values calculated for the successive periods of recording or hourly AUC were similar with both regimens and did not differ from those calculated during the usual diet period.

The same motor profile (AUC and NW values low before lunch and at night, increased after lunch and on awakening in the morning) as that found with the habitual diet was observed during both supplementation periods. This significant colonic motor response during the first $0.5 \mathrm{~h}$ after lunch was observed at all levels but this was significant only in 

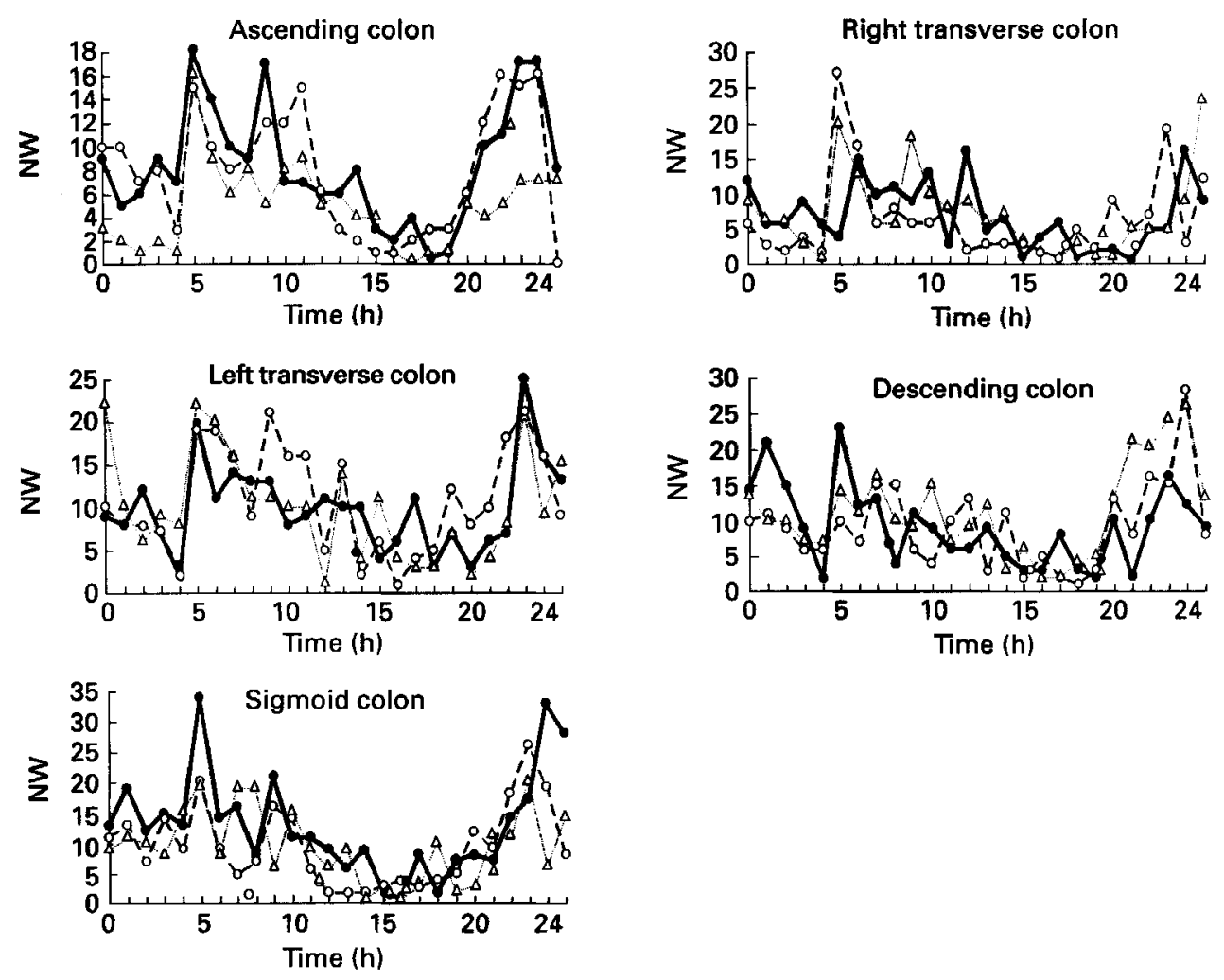

Fig. 2. Median number of pressure waves (NW) measured at five sites in the large intestine, for six male subjects consuming their habitual diet $(O)$, and diets supplemented with $15 \mathrm{~g}$ fibre from pea hulls $(O)$ or carrots $(\triangle)$ daily. For details of diets and procedures, see pp. 52-54.

the left transverse colon in the case of supplementation with fibre from pea-hull $(P<0 \cdot 02)$. It was more diffuse, from the right transverse colon to the sigmoid $(P<0.02)$ in the case of supplementation with carrot fibre (Table 3).

\section{DISCUSSION}

The present study demonstrated that daily chronic supplementation of the habitual diet with $15 \mathrm{~g}$ pea-hull or carrot fibre was easy and well tolerated. It did not induce major changes in the colonic motor patterns of healthy volunteers. Thus, the fibre we tested appears to be suitable for the preventive enrichment of the diet recommended by the World Health Organization (Spiller, 1986). In our study, however, when compared with the habitual diet, enrichment of the regimen with two types of dietary fibre, particularly that extracted from carrots, led to a more distal initiation of HAPC.

To reach some practical conclusions the present study was performed after a 3-week supplementation of the habitual diet because it has been shown that the specific motor effects of some nutrients, i.e. lipids (Cunningham et al. 1991) and carbohydrates (Edelbroek et al. 1992), are modulated by their presence or absence in the diet and by their degree of mixing with other types of nutrients (De Wever et al. 1978). This delay was introduced so that the colonic microflora, which metabolizes fibre, could adapt to this chronic supplementation, a process that takes approximately 1 week (Florent et al. 1985). Our 
methodology for the assessment of colonic motility was original and remained as close as possible to physiological conditions: motor studies were performed on unprepared colons with a manometric device introduced by nasal intubation and migrating spontaneously along the intestine. Recording sessions were performed after a mean delay of $3 \mathrm{~d}$, when all volunteers were well accustomed to the manometric tube. Our method differed widely from those reported previously where manometric recordings were limited to the left colon (Narducci et al. 1987; Bassotti \& Gaburri, 1988; Bassotti et al. 1989, 1992, 1994; MorenoOsset et al. 1989; Crowell et al. 1991; Reddy et al. 1991) and from those in which data were obtained through electromyographic studies including the whole length of the large bowel (Dapoigny \& Sarna, 1991) cleansed by enema to facilitate the endoscopic positioning of the probe. Dinoso et al. (1983) have shown that contractile activity is greater after a cleansing enema than in an unprepared colon. In these studies, preparation for endoscopy may have been an additional factor modifying the colonic motor profile. The present study did not reproduce all physiological conditions because our volunteers were resting in bed during the recording. It has been shown that physical activity stimulates both the frequency of the propagated contractions (Dapoigny \& Sarna, 1991) and the occurrence of HAPC (MorenoOsset et al. 1989; Crowell et al. 1991). Ambulatory conditions are an ideal background when assessing colonic motility in physiological conditions but only HAPC may be detected (a mean of two to six motor events per day) (Bassotti \& Gaburri, 1988; Crowell et al. 1991; Bassotti et al. 1992) with the presently available recording devices. This gives a very limited image of colonic motility.

In the present study the effects of both supplemented diets were compared with those of a habitual diet. We did not consider using a regimen enriched with wheat bran as a control diet. In our opinion, for healthy subjects, wheat bran does not meet all the criteria necessary for a fibre to satisfy the preventive dietary recommendations of the World Health Organization. To meet these criteria the fibre has to be easily ingested and well tolerated at a level of $15 \mathrm{~g}$ daily during long-term supplementation and maintain the physiological status of the subject. A diet supplemented with wheat bran is sometimes poorly tolerated; in previous trials bloating or abdominal pain have led about $15 \%$ of the subjects to discontinue its intake (Lucey et al. 1987; Cook et al. 1990). Moreover, wheat bran has been shown to affect colonic physiology mainly by decreasing transit time and modifying colonic motility (Burkitt et al. 1972; Payler et al. 1975; Cummings, 1981; Muller-Lissner, 1988; Cummings et al. 1992). Although this property is useful in patients with colonic dysfunction and constipation (Cowgill \& Andersson, 1932; Muller-Lissner, 1993) it could represent a drawback in healthy subjects.

The colonic motor changes occurring with both fibre-supplemented diets were minor and $24 \mathrm{~h}$ motor profiles remained unchanged. The colonic motor response to food, which occurs mainly during the first hour following a meal, as shown by Snape et al. (1978), was similar in the three diet periods. In agreement with Bassotti et al. (1989), Bazzochi et al. (1990) and Tomlin et al. (1991), we have observed that transverse and descending colons are the most important areas in which to detect a colonic motor response to food. The absence of sigmoid motor response observed in the present study, also reported by Bazzochi et al. (1990), but at variance with other authors (Moreno-Osset et al. 1989), could be partly explained by our limited number of sigmoid recordings. AUC, recognized criteria to quantify colonic motor activity (Moreno-Osset et al. 1989; Reddy et al. 1991; Bassotti et al. 1992), were also similar when the successive half-hour AUC or AUC calculated on the total recording were compared in the three studies carried out in all volunteers. Finally, with all regimens, HAPC were more frequent during the day, after meals and on awakening, as previously described (Bassotti \& Gaburri 1988; Crowell et al. 1991).

The lack of significant effect on colonic motor profile could be related to the fine particle 
size (less than $100 \mu \mathrm{m}$ ) of the fibre preparations we selected and our results are in accordance with those of Tomlin \& Read (1988) who consider that the physical properties of a fibre explain its motor effects. On the other hand, the hygroscopic properties and the fermentability seem to be of little influence on motor changes because the two types of fibre had the same minor motor effects in the present study despite very different hygroscopic properties and fermentability.

However, we have demonstrated that enrichment of the diet affects significantly the site of initiation of HAPC. With the habitual diet, in accordance with the findings of Bassotti \& Gaburri (1988), we found that HAPC always start from the ascending colon. When the diet was supplemented with either type of fibre we observed a more distal initiation of HAPC. This could mean a negative effect of the adjunction of fibre if we consider that HAPC are the motor expression of mass movements (Bassotti \& Gaburri, 1988; Bassotti et al. 1988) and that ascending and transverse colons act mainly as storage areas for faecal content (Proano et al. 1990). This prolonged storage could enhance short-chain fatty acid production through microbial fermentation. The colonic motor (Kamath et al. 1988) and trophic effects of the short-chain fatty acids are well known (Reilly et al. 1995). Thus an increased production could have deleterious effects in the long term.

In conclusion, chronic supplementation of the diet with dietary fibre extracted from pea hulls or carrots was easy because of acceptable taste and good clinical digestive tolerance and it did not modify colonic motor profiles. This supplementation satisfied almost all the conditions that we considered necessary to allow long-term supplementation of the habitual diet in healthy volunteers. The effects of a more distal initiation of HAPC need to be investigated.

\section{REFERENCES}

Arndorfer, R. C., Stef, J. J., Dodds, W. J., Linehan, J. H. \& Hogan, W. J. (1977). Improved infusion system for intraluminal esophageal manometry. Gastroenterology 73, 23-27.

Bassotti, G., Betti, C., Fusaro, C. \& Morelli, A. (1992). Colonic high-amplitude propagated contractions (mass movements): repeated $24 \mathrm{~h}$ manometric studies in healthy volunteers. Journal of Gastrointestinal Motility 4 , $187-191$

Bassotti, G., Betti, C., Imbimbo, B. P., Pelli, M. A. \& Morelli, A. (1989). Colonic motor response to eating: a manometric investigation in maximal and distal portions of the viscus in man. American Journal of Gastroenterology 84, 118-122.

Bassotti, G. \& Gaburri, M. (1988). Manometric investigation of high-amplitude propagated contractile activity of the human colon. American Journal of Physiology 255, G660-G664.

Bassotti, G., Gaburri, M., Imbimbo, B. P., Morelli, A. \& Whitehead, W. E. (1994). Distension-stimulated propagated contractions in human colon. Digestive Diseases and Sciences 9, 1955-1960.

Bassotti, G., Gaburri, M., Imbimbo, B. P., Rossi, L., Farroni, F., Pelli, M. A. \& Morelli, A. (1988). Colonic mass movements in idiopathic chronic constipation. Gut 29, 1173-1179.

Bazzochi, G., Ellis, J., Villanueva-Meyer, J., Jing, J., Reddy, S. N., Mena, I. \& Snape, W. J. (1990). Postprandial colonic transit and motor activity in chronic constipation. Gastroenterology 98, 686-693.

Burkitt, D. P., Walker, A. R. P. \& Painter, N. S. (1972). Effect of dietary fibres on stools and transit times, and its role in the causation of disease. Lancet ii, 1408-1412.

Cook, I. J., Irvine, E. J., Campbell, D., Shannon, S., Reddy, S. N. \& Collins, S. M. (1990). Effect of dietary fiber on symptoms and rectosigmoid motility in patients with irritable bowel syndrome. Gastroenterology 98, 66-72.

Cowgill, G. R. \& Andersson, W. E. (1932). Laxative effects of wheat bran and 'washed bran' in healthy men. Journal of the American Medical Association 98, 1866-1875.

Crowell, M. D., Bassotti, G., Cheskin, L. J., Schuster, M. M. \& Whitehead, W. E. (1991). Method for prolonged ambulatory monitoring of high-amplitude propagated contractions from colon. American Journal of Physiology 261, G263-G268.

Cummings, J. H. (1981). Dietary fibre. British Medical Bulletin 37, 67-70.

Cummings, J. H., Bingham, S. A., Heaton, K. W. \& Eastwood, M. A. (1992). Fecal weight, colon cancer risk and dietary intake of non-starch polysaccharides (dietary fibre). Gastroenterology 103, 1783-1789.

Cunningham, K. M., Daly, J., Horowitz, M. \& Read, N. W. (1991). Gastrointestinal adaptation to diets of differing fat composition in human volunteers. Gut 32, 483-486.

Dapoigny, M. \& Sarna, S. K. (1991). Effect of physical exercise on colonic motor activity. American Journal of Physiology 260, G646-G652. 
De Wever, I., Eeckout, C., Van Trappen, G. \& Hellemans, J. (1978). Disruptive effect of test meals on interdigestive motor complex in dogs. American Journal of Physiology 235, E661-E665.

Dinoso, V. P., Murthy, S. N. S., Goldstein, J. \& Rossner, B. (1983). Basal motor activity of the distal colon: a reappraisal. Gastroenterology $85,637-642$.

Drossman, D. A., Sandler, R. S., McKee, D. \& Lovitz, A. J. (1982). Bowel patterns among subjects not seeking health care. Use of questionnaire to identify a population with bowel dysfunction. Gastroenterology 83, 529-534.

Edelbroek, M., Horowitz, M., Fraser, R., Wishart, J., Morris, H., Dent, J. \& Akkermans, L. (1992). Adaptative changes in the pyloric motor response to intraduodenal dextrose in normal subjects. Gastroenterology 103 , 17541761.

Englyst, H. N. (1981). Determination of carbohydrate and its composition in plant materials. In Basic and Clinical Nutrition. The Analysis of Dietary Fibre in Food, vol. 3, pp. 71-93. [W. P. T. James and O. Theander, editors]. New York: Marcel Dekker Inc.

Florent, C., Flourie, B., Leblond, A., Rautureau, M., Bernier, J.-J. \& Rambaud, J.-C. (1985). Influence of chronic lactulose ingestion on the colonic metabolism of lactulose in man (an in vivo study). Journal of Clinical Investigation 75, 608-613.

Kamath, P. S., Phillips, S. F. \& Zinsmeister, A. R. (1988). Short-chain fatty acids stimulate ileal motility in humans. Gastroenterology 95, 1496-1502.

Lucey, M. R., Clark, M. L., Lowndes, J. O. \& Dawson, A. M. (1987). Is bran efficacious in irritable bowel syndrome? A double-blind placebo controlled cross-over study. Gut 28, 221-225.

Moreno-Osset, E., Bazzochi, G., Lo, S., Trombley, B., Ristow, E., Reddy, S. N., Villanueve-Meyer, J., Fain, J. W., Jing, J., Mena, I. \& Snape, W. J. (1989). Association between postprandial changes in colonic intraluminal pressure and transit. Gastroenterology $96,1265-1273$.

Muller-Lissner, S. (1988). Effect of wheat bran on weight of stool and gastrointestinal transit time: a metaanalysis. British Medical Journal 296, 615-617.

Muller-Lissner, S. (1993). Constipation and irritable bowel syndrome. European Journal of Gastroenterology and Hepatology 8, 587-592.

Narducci, F., Bassotti, G., Gaburri, M. \& Morelli, A. (1987). Twenty-four hour recording of colonic motor activity in healthy man. Gut $\mathbf{2 8}, 17-25$.

Payler, D. K., Pomare, E. W., Heaton, K. W. \& Harvey, R. F. (1975). The effect of wheat bran on intestinal transit. Gut 6, 209-213.

Picon, L., Lemann, M., Flourie, B., Rambaud, J.-C., Rain, J.-D. \& Jian, R. (1992). Right and left colonic transit after eating assessed by a dual isotopic technique in healthy humans. Gastroenterology 103, 80-85.

Proano, M., Camilleri, M., Philips, S. F., Brown, M. L. \& Thomforde, G. M. (1990). Transit of solids through the human colon: regional quantification in the unprepared bowel. American Journal of Physiology $\mathbf{2 5 8}$ G856-G862.

Reddy, S. N., Bazzochi, G., Chan, N. S., Akashi, K., Villanueve-Meyer, J., Yanni, G., Mena, I. \& Snape, W. J. (1991). Colonic motility and transit in health and ulcerative colitis. Gastroenterology 101, 1289-1297.

Reilly, K. J., Frankel, W. L., Bain, A. M. \& Rombeau, J. L. (1995). Colonic short chain fatty acids mediate jejunal growth by increasing gastrin. Gut 37, 81-86.

Salvador, V., Cherbut, C., Barry, J.-L., Bertrand, D., Bonnet, C. \& Delort-Laval, J. (1993). Sugar composition of dietary fibre and short-chain fatty acid production during in vitro fermentation by human bacteria. British Journal of Nutrition 70, 189-197.

Sarna, S. K. (1991). Physiology and pathophysiology of colonic motor activity. Digestive Diseases and Sciences 36, 998-1018.

Snape, W. J., Matarazzo, S. A. \& Cohen, S. (1978). Effect of eating and gastrointestinal hormones on human colonic myoelectrical and motor activity. Gastroenterology 75, 373-378.

Soffer, E. E., Scalabrini, P. \& Wingate, D. L. (1989). Prolonged ambulant monitoring of human colonic motility. American Journal of Physiology 257, G601-G606.

Spiller, G. A. (1986). Suggestions for a basis on which to determine a desirable intake of dietary fiber. In Handbook of Dietary Fiber in Human Nutrition, pp. 281-283 [G. A. Spiller, editor]. Boca Raton: CRC Press Ltd.

Tomlin, J., Brown, S. R., Cann, P. A. \& Read, N. W. (1991). Is rectosigmoid response to food modulated by proximal colon stimulation? Digestive Diseases and Sciences 36, 1481-1485.

Tomlin, J. \& Read, N. W. (1988). Laxative properties of plastic particles. British Medical Journal 297, $1175-1176$. 